\title{
Adenocarcinoma arising in sigmoid colon neovagina 53 years after construction
}

\author{
Kazunosuke Yamada ${ }^{1 *}$ (D, Dai Shida ${ }^{1}$, Tomoyasu Kato ${ }^{2}$, Hiroshi Yoshida ${ }^{3}$, Shigetaka Yoshinaga ${ }^{4}$ \\ and Yukihide Kanemitsu' ${ }^{1}$
}

\begin{abstract}
Background: In view of the rarity of vaginal agenesis, malignancy arising in the neovagina is extremely rare.

Case presentation: Here, we report a 76-year-old female with an adenocarcinoma arising in the sigmoid colon neovagina which was constructed 53 years ago for congenital vaginal agenesis. Vaginal endoscopy to examine vaginal bleeding revealed a protruding lesion occupying three quarters of the lumen in the vicinity of anastomosis of the residual vagina and sigmoid colon. Transvaginal ultrasonography revealed the muscularis propria layer (hypoechoic fourth layer) to be interrupted. CT revealed no distant metastasis. Total pelvic exenteration was performed based on the diagnosis of neovaginal cancer at the anastomosis site. The $45-\mathrm{mm}$ tumor showed well-differentiated adenocarcinoma with a mucinous adenocarcinoma component. Immunohistochemistry showed no p16-overexpressing tumor cells, suggesting the lack of human papilloma virus infection.
\end{abstract}

Conclusions: Although rare, clinicians should be aware of cancer that arises in the ectopic intestine when anastomosed with other organs.

Keywords: Neovagina, Vaginal agenesis, Sigmoid colon neovagina, Adenocarcinoma, Colon carcinogenesis

\section{Background}

Neovaginal construction/reconstruction is indicated for cases of congenital vaginal agenesis which is an uncommon genital tract anomaly that is reported to occur in 1 per 4000-5000 newborn females [1, 2], as well as genetic sexual ambiguity, vaginal loss resulting from gynecologic cancer, or post-traumatic injury and male to female transsexualism [3, 4]. Multiple vaginal reconstructive techniques have been reported, including bowel flaps, skin grafts, peritoneal grafts, and musculofasciocutaneous flaps [5]. Among these, the sigmoid colon is used most often in neovaginal reconstruction, given its unique characteristics, such as its close proximity to the operative site, morphology, and capacity to replicate vaginal function. Moreover, its thicker mucosa is less vulnerable to trauma induced by coitus $[6,7]$.

Primary vaginal carcinoma is extremely rare, accounting for only about $2 \%$ of malignant neoplasms of the female genital tract [8]. Moreover, in view of the rarity of

\footnotetext{
* Correspondence: kazunosukefukudai@yahoo.co.jp

'Department of Colorectal Surgery, National Cancer Center Hospital, 5-1-1

Tsukiji, Chuo-ku, Tokyo 1040045, Japan

Full list of author information is available at the end of the article
}

vaginal agenesis, malignancy arising in the neovagina is extremely rare. To date, only seven cases of adenocarcinoma arising in the neovagina have been reported in English publications, and of these, six cases of adenocarcinoma of the neovagina arose in the colon and one from the small intestine [9-15]. Here, we report a case of adenocarcinoma arising in the neovagina of a patient with Mayer-RokitanskyKüster-Hauser syndrome [16], which refers to the congenital aplasia or severe hypoplasia of the structures that derive from the mullerian ducts, occurring 53 years after initial neovagina construction.

\section{Case presentation}

Fifty-three years ago, a 23-year-old Japanese woman was referred to the outpatient clinic of our hospital with primary amenorrhea. Examination revealed normal external genitalia and an absent vagina. She was diagnosed with Mayer-Rokitansky-Küster-Hauser syndrome. Hereditary disease was excluded based on family history. She underwent neovaginal construction surgery using a segment of the sigmoid colon. At the age of 45 , she underwent hysterectomy for uterine myoma. At the age of 76, she visited the original outpatient clinic with the chief 
complaint of vaginal bleeding. Vaginal endoscopy confirmed anastomosis of the residual vagina with the sigmoid colon and revealed a $4.5-\mathrm{cm}$ protruding lesion in the vicinity of anastomosis, occupying about three quarters of the lumen (Fig. 1a). Biopsy from the protruding lesion revealed well-differentiated adenocarcinoma.

Transvaginal ultrasonography revealed the muscularis propria layer (hypoechoic fourth layer) to be interrupted with an unclear layer pattern and invasion of a hyperechoic tumor beyond the colon wall (Fig. 1b). The lesion was diagnosed as clinical T3 or deeper, and endoscopic resection was not indicated. T2-weighted MR imaging showed the neovagina, which extended from the vaginal opening to abdominal cavity, to exist between the bladder and rectum (Fig. 2). A 4.5-cm protruding lesion was detected along the posterior neovaginal wall. The rectum and urethra appeared to be free of invasion. CT showed no evidence of lymph node or distant metastasis. Colonoscopy of the remnant colon and rectum did not reveal any abnormalities. Tumor marker levels were as follows: CEA $2.5 \mathrm{ng} / \mathrm{ml}$, CA19-9 $20 \mathrm{U} / \mathrm{ml}$, CA125 $14 \mathrm{U} / \mathrm{ml}$, and SCC $0.8 \mathrm{ng} / \mathrm{ml}$, all of which were within the normal range. Based on the preoperative diagnosis of adenocarcinoma arising in the sigmoid colon neovagina 53 years after construction, we performed total pelvic exenteration for curative resection.

Intraoperatively, the blind end of the neovagina was confirmed on the retroperitoneum side of the remnant sigmoid colon. In the pelvis, the neovagina passed through the antimesenteric side and anterior wall of the rectum and was anastomosed with the vaginal opening (Fig. 3). Intra-abdominal dissemination and ascites were not found. The operative time was $8 \mathrm{~h}$ and $20 \mathrm{~min}$, and blood loss was $385 \mathrm{ml}$. The tumor was located in the vicinity of the anastomosis site and was macroscopically a $4.5-\mathrm{cm}$ protruding lesion. Adjacent tissues such as the urethra and labia minora were free of invasion (Fig. 4a, b).
Pathological examination revealed that radial margins were all negative and an adequate surgical margin was obtained. Sixteen lymph nodes retrieved by lymph node dissection were all free of tumor cells. The histology showed well-differentiated tubular adenocarcinoma in the surface area of the tumor (Fig. 4d), with a mucinous adenocarcinoma component in the invasive portion (Fig. 4e). Immunohistochemistry revealed no p16-overexpressing tumor cells, suggesting the lack of human papilloma virus (HPV) infection (Fig. 4f). The carcinoma penetrated into the submucosal layer of the neovagina without any evidence of vascular or lymphatic invasion. According to the TNM classification eighth edition [17], the ectopic colon cancer was categorized as T2NOM0, or stage I colon cancer, and thus, the patient did not undergo adjuvant therapy. The postoperative course was uneventful, and she was discharged on postoperative day 29. At present, 7 months postoperatively, the patient has neither symptoms nor apparent signs of recurrence.

\section{Discussion and conclusions}

Neovaginal carcinoma is extremely rare, whereas vaginal cancer which accounts for about $2 \%$ of all gynecological malignancies [8]. Schober et al. summarized the 30 cases of neovaginal carcinoma reported worldwide; of these, eight were adenocarcinomas arising from the intestinal grafts, and 17 were squamous cell carcinoma arising from the skin and the skin graft [18]. Thus, the pathological characteristics of this cancer are likely associated with the tissue used for reconstruction.

A literature search of "neovagina" and "adenocarcinoma" using PubMed yielded only seven cases of neovaginal adenocarcinoma (in which the intestine was used for construction) in the English literature. Of these, six cases of neovaginal adenocarcinoma originated from the colon and one case from the small intestine [9-15]. Our case is the seventh case of neovaginal adenocarcinoma
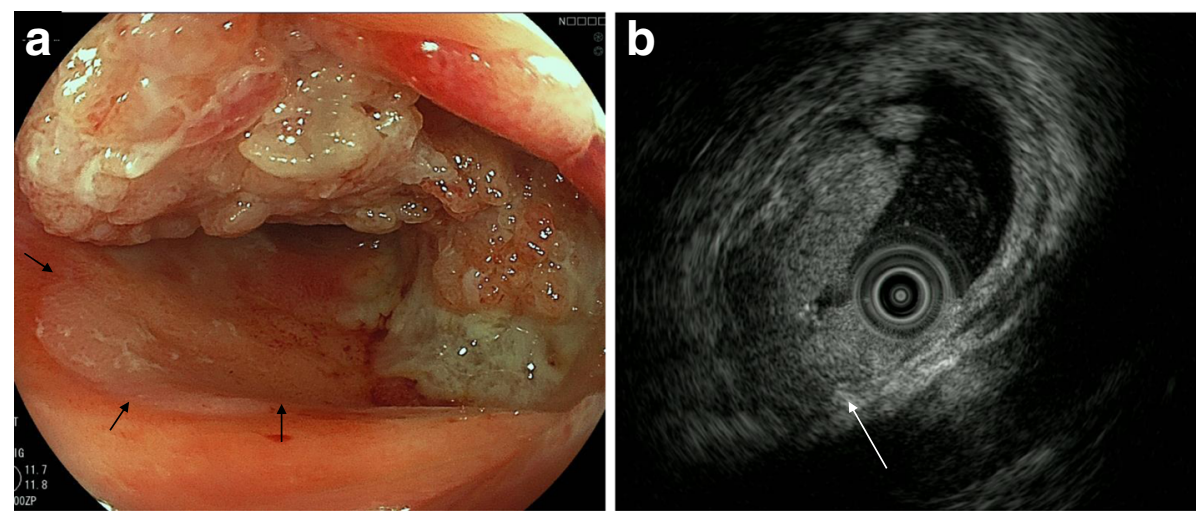

Fig. 1 a Transvaginal endoscopy. Anastomosis of ectopic sigmoid colon with residual vagina (black arrows). A 45-mm protruding lesion was observed in the vicinity of the anastomosis site, occupying about three quarters of the lumen. $\mathbf{b}$ Transvaginal ultrasonography. Muscularis propria layer (hypoechoic fourth layer) was interrupted with an unclear layer pattern. Hypoechoic tumor appeared to invade beyond the colon wall (white arrow) 


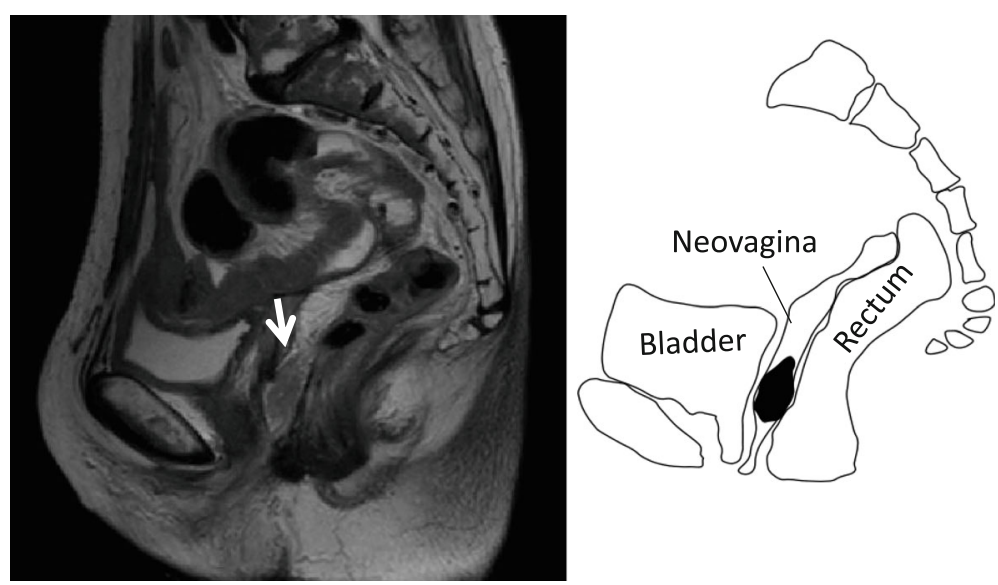

Fig. 2 T2-weighted MR image. The neovagina existed between the bladder and rectum and extended from the vaginal opening to abdominal cavity. A 4.5-cm protruding lesion (white arrow) was detected along the posterior neovaginal wall

involving the colon. Operative methods differed by case. For example, Hiroi et al. [11] performed total resection of the neovagina and bilateral salpingooophorectomy. Bogliolo et al. [13] performed subtotal vaginectomy and total radical hysterectomy with left salpingo-ovariectomy. Kita et al. [14] initially planned to remove only the neovagina, but switched to posterior pelvic exenteration due to substantial adhesion of the neovagina to the rectum and bladder. Thus, adhesion is an important factor to consider when planning surgery. As discussed above, there is no consensus operative strategy for these patients. In the present case, we diagnosed the patient with advanced cancer according to transvaginal ultrasonography and also anticipated strong adhesion of the neovagina to the rectum and bladder. Based on this, we considered it difficult to resect only the neovagina. In the end, we

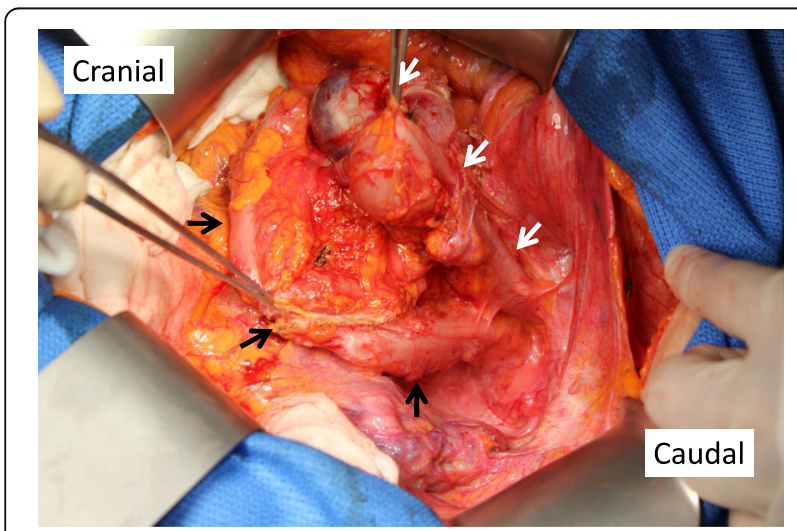

Fig. 3 Intraoperative findings. Blind end of the neovagina was confirmed on the retroperitoneum side of the remnant sigmoid colon. In the pelvis, the neovagina passes through the antimesenteric side and anterior wall of the rectum and was anastomosed with the vaginal opening (white arrows: neovagina, black arrows: remnant sigmoid colon) performed total pelvic exenteration in order to achieve complete resection with microscopic negative margins (R0).

Numerous risk factors associated with colon cancer have been reported, including age, sex, race, dietary habits, consumption of red meat, obesity, toxic substances such as tobacco, alcohol intake, and host factors [19-22]. Chronic inflammatory processes in the colon including ulcerative colitis and Crohn's disease are also associated with an increased risk of developing colorectal cancer [23]. The present case report clearly demonstrated the potential occurrence of malignancy in ectopic intestinal tissue used for neovaginal construction. It is easily conceivable that the ectopic colon, although anatomically excluded and separate from the influence of two potential factors that promote cancer development (i.e., bile acid and direct contact with potentially carcinogenic food), retains the basic properties of the remaining large bowel, including genetic factors (e.g., oncogenic activation) involved in cancer development. Notably, as with our present case, neovaginal adenocarcinoma (which involved the sigmoid colon) was located in the vicinity of the anastomosis site in four of five previously reported cases. Other than the neovagina, secondary malignancy at the uroenteric anastomosis site is a well-documented long-term complication after ureterosigmoidostomy. Ectopic colon cancer occurred at the ureterocolonic junction with an 8.5- to 10.5-fold increased risk of colon carcinoma compared to the general population [24]. Moreover, p53 mutations, which are indicative of genetic instability, are known to occur at the ileovesical anastomosis site in patients who have undergone clam ileocystoplasty, which results in neoplasia after ureterosigmoidostomy at uroenteric anastomosis sites [25]. Chemical stimulants in semen and urine may have contributed to malignancy in these previous cases. These reports, as well as our present case, 


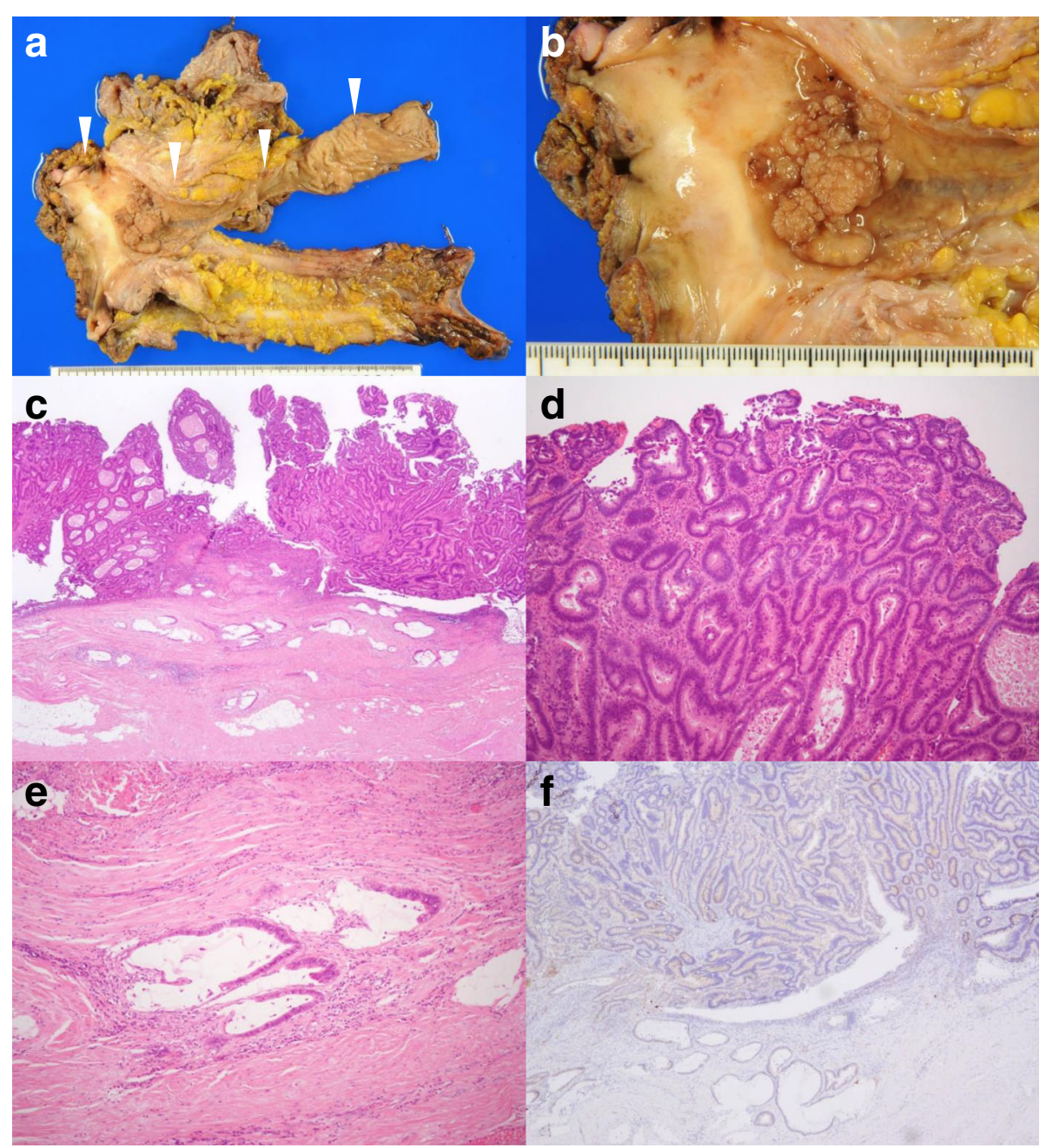

Fig. 4 Pathological examination of resected specimen. a Tumor located in the neovagina constructed with ectopic sigmoid colon (white arrow heads). b A tan-colored papillary elevated tumor was observed in the neovagina. c Low magnification of the tumor (H\&E, original magnification $\times 20$ ). d At higher magnification, a well-differentiated tubular adenocarcinoma was observed in the surface area of the tumor ( $\mathrm{H} \& \mathrm{E}$, original magnification $\times 100$ ). e Mucinous adenocarcinoma component in the invasive portion (H\&E, original magnification $\times 100$ ). $\mathbf{f} I$ mmunohistochemistry revealed no p16-overexpressing tumor cells (original magnification $\times 40$ )

suggest that intestinal anastomosis with other organs may increase the risk of cancer.

HPV infection is a well-established cause of invasive cervical cancer, and there is an increasing body of evidence strongly linking HPV DNA with other anogenital cancers (anus, vulva, vagina, and penis) and head and neck cancers (particularly the oropharynx, base of the tongue, and tonsils) [26]. However, with respect to adenocarcinoma occurring in the sigmoid colon neovagina, our case was immunohistochemically negative for the p16 protein, as were the three previous cases for which p16 was examined. These results suggest that adenocarcinoma occurring in the sigmoid colon neovagina may be independent of HPV infection.

In conclusion, we encountered a patient with a rare carcinoma in the sigmoid colon neovagina. To achieve complete resection with microscopic negative margins for advanced neovaginal cancer, total pelvic exenteration is a good surgical option. Although rare, clinicians should be aware of cancer arising in the ectopic intestine when anastomosed with other organs, given the persistent risk of malignant transformation.

\section{Abbreviations}

HPV: Human papilloma virus

\section{Acknowledgements}

The authors thank Takahashi K, Kobayashi M, Tanabe T, Ochiai H, and Tsukamoto $\mathrm{S}$, all of whom served as staff members in National Cancer Center Hospital. 


\section{Availability of data and materials}

The data supporting the conclusions of this article are included within the manuscript.

\section{Authors' contributions}

KY and DS designed the report, analyzed the data, and wrote the manuscript; TK, SY, and YK collected the patient's clinical data and coordinated and helped draft the manuscript; and HY performed the pathological diagnosis and wrote part of the manuscript. All authors read and approved the final manuscript.

\section{Ethics approval and consent to participate}

Ethics approval was obtained from our hospital's review board (NCC2014-414).

\section{Consent for publication}

Written informed consent was obtained by the patient.

\section{Competing interests}

The authors declare that they have no competing interests.

\section{Publisher's Note}

Springer Nature remains neutral with regard to jurisdictional claims in published maps and institutional affiliations.

\section{Author details}

${ }^{1}$ Department of Colorectal Surgery, National Cancer Center Hospital, 5-1-1 Tsukiji, Chuo-ku, Tokyo 1040045, Japan. ${ }^{2}$ Department of Gynecology, National Cancer Center Hospital, Tokyo 1040045, Japan. ${ }^{3}$ Department of Pathology and Clinical Laboratories, National Cancer Center Hospital, Tokyo 1040045, Japan. ${ }^{4}$ Department of Endoscopy, Gastrointestinal Endoscopy Division, National Cancer Center Hospital, Tokyo 1040045, Japan.

Received: 2 September 2017 Accepted: 19 March 2018

Published online: 27 April 2018

\section{References}

1. Aittomaki K, Eroila H, Kajanoja P. A population-based study of the incidence of Mullerian aplasia in Finland. Fertil Steril. 2001;76:624-5.

2. Committee on Adolescent Health C. ACOG Committee opinion no. 728: Mullerian agenesis: diagnosis, management, and treatment. Obstet Gynecol. 2018;131:e35-42.

3. O'Connor JL, DeMarco RT, JCt P, Adams MC, Brock JW 3rd. Bowel vaginoplasty in children: a retrospective review. J Pediatr Surg. 2004;39:1205-8.

4. ACOG Committee on Adolescent Health Care. ACOG Committee opinion no. 355: vaginal agenesis: diagnosis, management, and routine care. Obstet Gynecol. 2006;108:1605-9.

5. Pusic AL, Mehrara BJ. Vaginal reconstruction: an algorithm approach to defect classification and flap reconstruction. J Surg Oncol. 2006;94:515-21.

6. Darai E, Toullalan O, Besse O, Potiron L, Delga P. Anatomic and functional results of laparoscopic-perineal neovagina construction by sigmoid colpoplasty in women with Rokitansky's syndrome. Hum Reprod. 2003;18:2454-9.

7. Urbanowicz W, Starzyk J, Sulislawski J. Laparoscopic vaginal reconstruction using a sigmoid colon segment: a preliminary report. J Urol. 2004;171:2632-5.

8. Hacker NF, Eifel PJ, van der Velden J. Cancer of the vagina. Int J Gynaecol Obstet. 2015;131(Suppl 2):S84-7.

9. Borruto F, Ferraro F. Adenocarcinoma of a neovagina constructed according to the Baldwin-Mori technique. Eur J Gynaecol Oncol. 1990;11:403-5.

10. Ursic-Vrscaj M, Lindtner J, Lamovec J, Novak J. Adenocarcinoma in a sigmoid neovagina 22 years after Wertheim-Meigs operation. Case report. Eur J Gynaecol Oncol. 1994;15:24-8.

11. Hiroi H, Yasugi T, Matsumoto K, Fujii T, Watanabe T, Yoshikawa H, Taketani Y. Mucinous adenocarcinoma arising in a neovagina using the sigmoid colon thirty years after operation: a case report. J Surg Oncol. 2001;77:61-4.

12. Schouten van der Velden AP, de Hingh $I H$, Schijf $C P$, Bonenkamp HJ, Wobbes T. Metachronous colorectal malignancies: "don't forget the neo vagina". A case report. Gynecol Oncol. 2005;97:279-81.

13. Bogliolo S, Gaggero CR, Nadalini C, lacobone AD, Musacchi V, Cassani C, Peroglio Carus A. Long-term risk of malignancy in the neovagina created using colon graft in vaginal agenesis - a case report. J Obstet Gynaecol. 2015;35:543-4.
14. Kita Y, Mori S, Baba K, Uchikado Y, Arigami T, Idesako T, Okumura H, Ishigami S, Nakagawa M, Natsugoe S. Mucinous adenocarcinoma emerging in sigmoid colon neovagina 40 years after its creation: a case report. World J Surg Oncol. 2015:13:213.

15. Andryjowicz E, Qizilbash AH, DePetrillo AD, O'Connell GJ, Taylor MH. Adenocarcinoma in a cecal neovagina-complication of irradiation: report of a case and review of literature. Gynecol Oncol. 1985;21:235-9.

16. Londra L, Chuong FS, Kolp L. Mayer-Rokitansky-Kuster-Hauser syndrome: a review. Int J Womens Health. 2015;7:865-70.

17. UICC. TNM classification of malignant tumours (eighth edition). New York: Wiley; 2017.

18. Schober JM. Cancer of the neovagina. J Pediatr Urol. 2007;3:167-70.

19. Larsson SC, Orsini N, Wolk A. Diabetes mellitus and risk of colorectal cancer: a meta-analysis. J Natl Cancer Inst. 2005;97:1679-87.

20. Herszenyi L, Miheller P, Tulassay Z. Carcinogenesis in inflammatory bowel disease. Dig Dis. 2007;25:267-9.

21. Hassan C, Pickhardt PJ, Marmo R, Choi JR. Impact of lifestyle factors on colorectal polyp detection in the screening setting. Dis Colon rectum. 2010; 53:1328-33.

22. Hoffmeister M, Schmitz S, Karmrodt E, Stegmaier C, Haug U, Arndt V, Brenner $\mathrm{H}$. Male sex and smoking have a larger impact on the prevalence of colorectal neoplasia than family history of colorectal cancer. Clin Gastroenterol Hepatol. 2010;8:870-6.

23. Elinav E, Nowarski R, Thaiss CA, Hu B, Jin C, Flavell RA. Inflammation-induced cancer: crosstalk between tumours, immune cells and microorganisms. Nat Rev Cancer. 2013:13:759-71.

24. Kalble T, Tricker AR, Friedl P, Waldherr R, Hoang J, Staehler G, Mohring K. Ureterosigmoidostomy: long-term results, risk of carcinoma and etiological factors for carcinogenesis. J Urol. 1990;144:1110-4.

25. Ivil KD, Jenkins SA, Doak SH, Hawizy AM, Kynaston HG, Parry EM, Jenkins GJ, Parry JM, Stephenson TP. Identification of early p53 mutations in clam ileocystoplasties using restriction site mutation assay. Urology. 2007;70:905-9.

26. Serrano B, de Sanjose S, Tous S, Quiros B, Munoz N, Bosch X, Alemany L. Human papillomavirus genotype attribution for HPVs 6, 11, 16, 18, 31, 33, 45, 52 and 58 in female anogenital lesions. Eur J Cancer. 2015;51:1732-41.

\section{Submit your next manuscript to BioMed Central and we will help you at every step:}

- We accept pre-submission inquiries

- Our selector tool helps you to find the most relevant journal

- We provide round the clock customer support

- Convenient online submission

- Thorough peer review

- Inclusion in PubMed and all major indexing services

- Maximum visibility for your research

Submit your manuscript at www.biomedcentral.com/submit
Biomed Central 